\title{
Téoros
}

Revue de recherche en tourisme

\section{Charlevoix, pays de culture} Pour combler un vide de sens

\section{Alain Boucher}

Volume 17, numéro 1, printemps 1998

Le tourisme dans un Pays à part : Charlevoix

URI : https://id.erudit.org/iderudit/1072369ar

DOI : https://doi.org/10.7202/1072369ar

Aller au sommaire du numéro

Éditeur(s)

Université du Québec à Montréal

ISSN

0712-8657 (imprimé)

1923-2705 (numérique)

Découvrir la revue

Citer cet article

Boucher, A. (1998). Charlevoix, pays de culture : pour combler un vide de sens. Téoros, 17(1), 5-8. https://doi.org/10.7202/1072369ar d'utilisation que vous pouvez consulter en ligne.

https://apropos.erudit.org/fr/usagers/politique-dutilisation/ 


\section{fin......}

\section{Charlevoix, pays de culture}

POUR COMBLER UN VIDE DE SENS

\begin{abstract}
Alain Boucher, intervenant touristique et enseignant Centre d'études collégiales de Charlevoix
\end{abstract}

Dans la seconde moitié du XVIIT siècle, une region isolée du reste du Québec, qui porte aujourd'hui le nom de Charlevoix. s'ouvre au monde en recevant ses premiers visiteurs touristiques, une clientèle tout à fait nouvelle. La rencontre sera déterminante pour l'histoire de Charlevoix. Le coup de foudre pour la nature démesurée de la région et pour la culture particulière de ses habitants dure encore aujourd hut, mème après plus de deux siècles. Cette culture qu' ont adulée tous les ethnologues, auteurs, journalistes, peintres, photographes et autres spécialistes, cette culture charlevoisienne si unique à leurs yeut est pourtan faile, à l'origine, de toutes petites choses du quotidien: une foi, une langue, une histoire, des métiers, des croyances, un sourire.

La rencontre sera profitable pour tout le monde. En echange de leur quotidien généreusement offert, les Charlevoisiens recevront une ouverture peu commune sur le monde, une reconnaissance de la qualité de leur production artistique et artisanale, du travail et surtout une image idylique d'eux-mêmes, propre à renforcer l'identité et la fierté nécessaire à la conservation des patrimoines culturels.

Avec le passage du Québec à la post-modernité, dans les années 1960, avec la chute puis la renaissance de l'industrie touristique, au fournant des années 1970, la culture de Charlevoin s'est diversiffe et complexifies. Produit touristique toujours très en demande, cette culture, maintenant à la fois authentique et artificielle, est en quête d'une nouvelle identité.

\section{QUELLE CULTURE?}

Le tourisme n'est plus ce qu'il était. Du voyage de plaisir qu'elle était à l'origine et jusqu'à récemment, cette activité est devenue une entreprise d'envergure mondiale, avec ses actuaires, son marketing. ses plans d'affaires, ses produits. Le discours touristique vient désormais de la bouche des économistes et des publicitaires puisque, comme dans toute industrie, il faut vendre pour vivre. Et dans ce discours, la Culture est à l'honneur, assise à la droite de la Nature, comme il se doit. Juste retour des choses, juste retour des valeurs qui ont alimente depuis l'origine cette rencontre d'êtres humains différents dans un environnement étranger.

La région touristique de Charlevoix n'a pas su résister à la tentation d'inscrire en tête d'affiche "Pays de nature et de culturew. Était-ce pour être à la page et concurrencer férocement? Les publicitaires auraient-ils plutôt saisi l'essence de la région? Plus probablement.

Les aléas de la morphologie de Charlevoix, combinés à la détermination de la population de s"y faire une place, ont livré un pays où nature et culture s'alimentent l'une de l'autre depuis trois siècles et, à la grande admiration des touristes d'hier et d'aujourd' hui, se livrent une lutte à la popularité.

Comment décrire maintenant cette culture de Charlevoix, en évitant le piège des afaiseurs de produits touristiques», sachant que Félix-Antoine Savard, le poète et homme de Dieu, qualifiait sa région d'adoption de acomté métaphysique qu'un villégiateur du siècle dernier en disait: "Charlevoix est un état d'esprits?

\section{CHARLEVOIX DE NOUVELLE-FRANCE, CHARLEVOIX DE QUÉBEC}

Entre 1675 et 1685, lorsque les Lavoie, Bouchard, Fortin, Simard et Tremblay s'installent en pionniers dans l'ouest de Charlevoix, venus de la côte de Beaupré, ils sont loin de s"imaginer que leurs efforts de colonisation dans ce pays de bout du monde donneront naissance à la dif= férence qui fera de Charlevoix l'une des destinations de dépaysement les plus recherchées.

D'un point de vue ethnohistorique, le développement de Charlevoix ne differe en rien de celui des autres régions du Québec. Le peuplement des seigneuries évolue au gré de l'énergie des seigneurs et au hasard des tracasseries administratives, pour être ensuite délesté vers les cantons d'arrière-pays puis réorganisé en municipalités; les institutions religieuses et civiles comblent, au fil des années, les besoins et les goûts d'une population toujours plus nombreuse: le quotidien suscite l'esprit d'entreprise et la débrouil- 
lardise dans tous les domaines de l'activité humaine. L'histoire suit lentement son cours.

Cependant, la situation géographique de la région aura, jusqu'à ces récentes années, un effet déterminant sur le rythme et l'importance de son développement. Les principaux villages de Charlevoix ne sont situés qu'à quelques dizaines de kilomètres de la ville de Québec, sur lat rive nord du fleuve Saint-Laurent: Baie-Saint-Paul à 100 kilomètres, La Malbaie à 150. Par contre, les montagnes et le fleuve qui séparent la région du reste du pays sont une barrière quasi infranchissable, remparts qui garderont le comté loin des influences extérieures jusqu" au début des annees 1960.

C'est dans cette région isolée, dans une société repliée sur elle-même que prendront forme des façons de faire et de voir bien ancrées au pays, une culture importee de France a l'otigine, puis tout doucement teintée d'Écosse, d'Etats-Unis et de Canada, au fil des décennies, mais toujour's servie «à la charlevoisiennew, une saveur tout à fait originale qui crée la véritable difference.

\section{VENIR AU MONDE}

A l'aube du Régime anglais, la nouvelle Province of Quebec s'ouvre au reste de l'Amérique et à l'Angleterre, deux nations qui montrent un intérêt inédit pour ce territoire de vieille France. L'oeil frais du touriste, ce voyageur nouvellement inventé, se pose sur une culture cachée par des frontières jalousement fermées durant près de deux siècles.

Dans Charlevoix, à Murray Bay et à Mount Murray, les visiteur's des nouveaux seigneurs écossais Naime et Fraser découvrent, outre des paysages qui comblent leurs pensées de romantiques à la mode, une organisation de l'écoumène et une architecture rurale tout à fait originales, parfaitement adaptées au climat et au relief de ce territoire unique dans le monde connu. Ils y entendent une langue familière, mais un dialecte imprévu, déjà «québécois», en plus d'un parler possiblement «charlevoisien avant l'heure. Ils y côtoient des gens pauvres de l'âpreté du pays et de la rareté des ressources, mais tellement riches de l'esprit d'entreprise et d'invention, de l'entraide et de l'hospitalité que suscitent l'indigence et l'iso- lement. On dispose de tout, en petite quantité, mais l'éloignement a fait naître dans cette société tous les métiers essentiels et toutes les occupations du corps et de l'esprit: musique, religion, domesticité, pratiques coutumières, activités traditionnelles, etc.

Au touriste nouveau des $\mathrm{XVIII}^{\mathrm{r}}$ et $\mathrm{XIX}^{\mathrm{c}}$ siècles, Charlevoix offre une nature accessible et sauvage à la fois et une culture du quotidien inusitée. Les voyageurs s'empresseront d'annoncer leur découverte d'une différence nouvelle, en images et en mots, sur les réseaux d'information naissants. Toutes les relations des premiers visiteurs et, plus tard, les guides de voyage et de séjour insistent sur ces aspects de la culture charlevoisienne et sur leur intérêt touristique. Des milliers d'yeux avides d'exotisme se tournent alors vers cette curiosité un peu anachronique qu'est la culture isolée, presque originelle des gens de Charlevoix, une culture faite des petites choses de tous les jours.

Au charme de la nature s'y ajoute le contact d'une population terrienne aimable et gaie, où sont gardées les traditions et les coutumes du passé. Ainsi, les femmes de la rive nord filent encore la laine et le lin a la cadence des vieilles chanwons du terroir normand. C'est là un des rares endroits de la province de Quebec où se fabriquent la toile et l'etoffe du pays. On y parle aussi un langage savoureux, emaille de proverbes et de vieux mots français. La clarté des idées, le gros bon sens et une politesse exquise rendent tres intéressante la conversation de ces gens, $x$

(Chemin de fer national du Canada, c 1925: 49)

Alertés par tant de bruit, les spécialistes de la culture se pressent à la suite des premiers relationnistes. Charlevoix sera arpentế par les observateurs de l'Amérique tout entière et faire une sélection des chantres de la région n'est pas chose facile. Le journaliste et chroniqueur Arthur Buies y a écrit de délicieuses pages, le romancier William Hume Blake a raconté en plusieurs volumes ses formidables explorations de l'arrière-pays, les photographes William Notman et Jules Livernois ont laisse des images parmi les plus evocatrices sur Charlevoix. Clarence Gagnon et combien d'autres peintres se sont ins- pirés de sa lumière et de ses gens. Le folkloriste Marius Barbeau, pere de l'ethnologie canadienne, y a fait ses premières armes et sa récolte le surprend et le réjouit:

* Les etrangers, tout comme moi, ne tardaient pas à remarguer, dans le comte de Charlevoix, des traits qui ne se retrouvent guère aillews. Par exemple, des expressions dans le parler, des tissus, des legumes, comme les gourganes, et aussi un trait particulier dans la construction des étables, qu'on nomme abatvents. o

(Barbeau, 1934: 53)

Le miroir du visiteur — et le nouveau marché! - ne tardera pas à inciter les visités à mettre en valeur toutes ces petites choses...

\section{CULTURE DES VISITEURS, CULTURE DES VISITÉS}

Petit à petit, les artisanes, artistes et gens de métiers de Charlevoix introduiront sur le marché régional une production destinée exclusivement aux touristes. Ces produits, tout en gardant une saveur profondément charlevoisienne, répondront toujours mieux aux goûts nouveaux d'une clientèle extérieure, apportant ainsi à la région une ouverture qu'elle n'avait jusque là pas connue.

Le plus bel exemple est celui dé la peinture. Lorsque le jeune peintre Clarence Gagnon arrive dans Charlevoix au début du XXe siecle, en plus des paysages qu'il s"empressera de reproduire et de promouvoir -encore ces mêmes paysages qui enchantèrent les premiers visiteurs des seigneurs écossais - il trouve une pépinière d'artistes que quelques conseils et encouragements feront éclore. Le couple d'estivants américains Maud Cabot et Patrick Morgan prendra le relais auprès des soeurs Simard, de la famille Bouchard, de Georges-Edouard Tremblay, d' Yvonne Bolduc et de tant d'autres peintres et sculpteurs autodidactes. En leur ouvrant le marché des résidents d'été, notamment lors des expositions annuelles d'Arts \& Crafts à La Malbaie et d'une exposition à la East River Gallery de New York au milieu des années 1930, les Morgan ont participé à la consécration nationale et internationale de ces artistes. 
De leur côté, les artistes-peintres continuaient d'affluer à Baie-Saint-Paul à l'invitation de Gagnon, puis de René Richard. Cette petite ville compte aujourd 'hui à elle seule plus d'une trentaine de boutiques et galeries d'art, un Centre d'exposition et un Centre d'art, dont le Symposium annuel ravit les amateurs du monde entier.

Les visiteurs aussi apportaient dans leurs. bagages des morceaux de culture, qu'ils laissaient volontiers aux Charlevoisiens en échange. On peut imaginer aisément la surprise des contracteurs de La Malbaie, Warren pere et fils, lisant un plan de villa dessine par un architecte new-yorkais et constatant avec stupeur que les murs porteurs de cette gigantesque maison aux formes nouvelles étaient vides, eux qui construisaient en pièces sur pièces. On se réjouit aujourd' hui de cette délicate grille de foyer fabriquée par le forgeron Cauchon à partir d un modèle fourni par une estivante de Toronto. Lordinaire alimentaire de toute une génération de Villeneuve a êté chambardé lorsque madame a êté engagée comme cuisinière achez les Américainsw. Thomas Fortin, le guide de l'arrière-pays de Charlevoix, a certainement revisé son concept de la féminité après avoir accompagné à maintes reprises. l'explorateur William Blake, ses amis et toutes ces adames de la villew dans de rudes équipees de chasse et de peche sur les hautes terres de lạ région.

La rencontre des visités et des visiteurs, dans les annees intenses du tourisme et de la villégiature, s'est faite avec un esprit d'accueil et d'ouverture peu commun de la part des uns et des autres. C est dans ce contexte que des cultures ont pu s'échanger, s'interpénétrer, se compléter et finalement grandir.

\section{LA CULTURE INSTITUTIONNELLE}

En cette fin de siècle, dans le contexte d'une concurrence touristique commerciale de plus en plus structurée, certains patrimoines charlevoisiens se sont reconnus et ont fait leur place dans le volet culturel de l'offre. Des musées sont nés pour préserver et présenter différents aspects de cette culture du quotidien. Le plus important est le Musée de Charlevoix, à La Malbaie - Pointe-au-Pic, voué à l'histoire, à l'ethnologic et aux arts populaires, avec également une préoccupation extra-régionale. Plusieurs autres institutions muséales, dont les nouveaux économusées, nés dans Charlevoix, s'intéressent ầ des facettes plus spécifiques: fabrication du fromage, goclettes et navigation fluviale, patrimoines historiques et technologiques locaux, histoire naturelle, architecture ou métiers.

D'autres institutions sont le fruit de la réflexion et du travail d'un seul individu, sans avoir de lien direct avec la culture propre de Charlevoix. L'Académie de musique du Domaine Forget, à Saint-Irénée. est une création du musicien et chef d'orchestre Françoys Bernier, d'abord estivant puis résident permanent; la $\mathrm{Pa}-$ peterie Saint-Gilles est le reve de l'écrivain Fellix-Antoine Savard, qui souffrait de voir s'étioler la tradition créatrice du geste au profit d'un art de catalogues, la Poterie de Port-au-Persil est née de la passion de Pierre Légault, céramiste de renom, qui souhaitait enseigner son art dans un cadre d'excellence.

D'autres entrepreneurs privés ont aussi saisi l'importance et l'intérêt de leur patrimoine culturel familial dans l'offre touristique. Chaque village ou presque abrite un commerce ou propose une activité où le touriste goûtera du sourife et de l'hospitalité et apprendra une page de la culture locale ou régionale. Boulangerie, forge, tissage et tricot, fromagerie, sucrerie, déplacements, agriculture, musique et chanson, chasse et peche sont tous mis en valeur, à la pièce ou regroupés à l'intérieur de circuits. Parmi ceux-là, citons en exemple les Fermes écho-touristiques et la Route des saveurs, qui regroupent des producteurs agricoles soucieux d'une ren= contre harmonicuse entre culture et Culture, et la Route de l'artiêre-pays, dont les membres offrent des activités et des services de découverte des attraits culturels et naturels du piémont de Charlevoix.

\section{L'AUTHENTIQUE ET L'ARTIFICIEL}

L'histoire de la villégiature, et plus récemment celle du tourisme en Charlevoix se lit en trois chapitres, tout comme celle de la culture charlevoisienne. Et, comme toute chose qui grandit, la rencontre entre le tourisme et la culture se complexifie.

Les premières années de fréquentation étaient empreintes de simplicité: le tou-

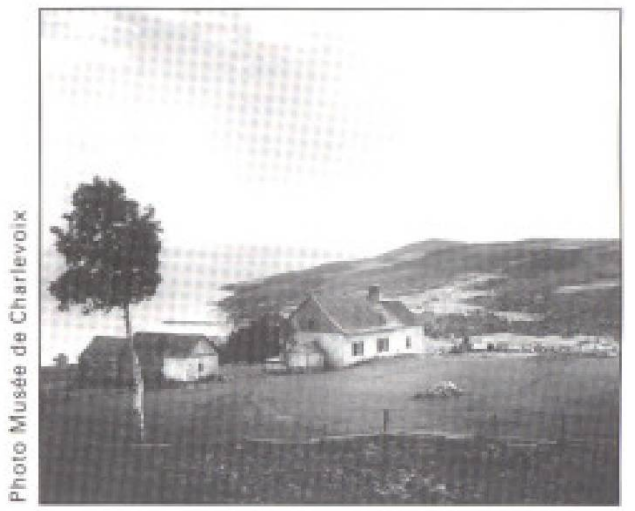

(Vue de la maison Jean, dans le rang Terrebonne a Saimt-Irenes, ), La relation etroite entre paysage, occupation du sol et patrimoine bati est un de ces fails de culture qui ont contribué à la renommée de Charlevoix. La maison Jean, à Saint-lrénéc, est une des grandes vedetles de la publicité touristique depuis les années 1980. Cette vue de la maison date pourtant des années $1910 \ldots$

riste découvrait l'autre, le Charlevoisien, dans une charmante nudité, candide et naturelle. C'était la tradition à l'état pur avec ses bons et ses mauvais côtés, la culture du quotidien qui s "offrait au regard un peu voyeur du touriste, un regard tout de meme plein d'admiration romantique et de respect pour ce nouveau joyau. C'était l'époque de l"authentique. puisqu'on ne connaissait pas encore bien les méthodes de fabrication d'une culture artificielle. C'était l'époque de la grande villégiature cossue de Murray Bay et bourgeoise de Saint-Irếnée des Éboulements-en-Bas. Ce fut aussi l'époque d'un tourisme plus simple, plus aventurier à l'ile aux Coudres, Baie-Saint-Paul et les environs.

Au milieu des années 1960 , cette époque que I'on se plait aujourd'hui à qualifier de belle s'est éteinte, emportée par l'aprèsguerre et les années glorieuses du rêve américain. Pendant près de 20 ans, puisque le vide est improbable, disons que le tourisme a eu le visage pâle et émacié de la culture régionale qu'on lui offrait. Le restaurant Chez Ti-Bé, près du Gas-Bar Golden Eagle, les chambres luxucuses du Motel Royal, avec leur tếlévision, leur téléphone et leur tapis (!) et le restaurant Le Gitan, avec ses charcoal steaks et son barsalon s'arrachaient les derniers braves qui osaient encore passer par Charlevoix. De leur côté, les descendants des villégiateurs d'autrefois restaient fidèles aux quelques institutions, pour la plupart anciennes, qui avaient su résister au raz-de-marée Coca- 
Cola. C'était l'arrivée en Charlevoix de cette culture artificielle fabriquéc ailleurs, par d'autres. Elle entrait à pleine porte par la route récemment ouverte à l'année entre Beaupré et Baie-Saint-Paul. C'était aussi l'agonie de la culture ancienne, folklorique et bien ancrée au pays. Charlevoix passait, dans la douleur et la laideur, à l'époque post-moderne.

Chapitre trois. La culture traditionnelle des gens de la région est encore vivante. malgré la révolution tranquille. Les ethnographes découvrent toujours avec stupéfaction les restes de cette culture isolée, un peu rafistolée, chez les grandsmères et, chose surprenante, aussi chez leurs petits-fils. Le tourisme dans Charlevoix se reconstruit sur ces solides fondations culturelles dès le début des années 1980. L'offre se complexific à mesure qu'elle reprend vie, ouverture sur le monde oblige. On voit naitre ce qu'est aujourd'hui le Musée de Charlevoix, les auberges qui ont fait notre récente renommée poussent ici et là, des galeries et le Centre d'art ouvrent leurs portes, le Domaine Forget fait ses premiers pas, les économusées et le Centre d'exposition sont les derniersnés. Ces institutions, bien que récentes et artificielles, c'est-à-dire fabriquées de toutes pièces, savent désormais offrir à une nouvelle clientèle un produit culturel adroitement composé d'authenticité charlevoisienne et de savantes techniques de mise en scène.

Le produit culturel de la région est maintenant entre les mains des scénographes, des concepteurs, des decorateurs et des muséologues. La sacralisation d'une part de culture s'est opérée à l'intention des visiteurs. Mais il reste l'autre part, celle qu'on ne saura jamais atouristifiers mais qui demeurera toujours le principal produit d'appel pour le touriste, cette différence tant recherchee: la culture des mécaniciens Tremblay kle Lièvres et de Louis à Maurice à Joseph, la soupe aux gourganes de madame Laberge, la mémoire du légendaire Alexis le Trotteur et la achouennew' de grand-papa Desgagnés sur le quai de Saint-Joseph-de-la-Rive.

\section{HORS LA RENCONTRE, POINT DE SALUT}

En Charlevoix plus qu'ailleurs au Québec, la culture est intimement liée à la nature. L'extravagante diversité du relief, les caux tumultueuses de l'estuaire du
Saint-Laurent, la pauvreté du sol arable I'omniprésence de la forêt et surtout l" isolement géographique ont tous, à leur manière, donné naissance ou exacerbé un trait de la culture des habitants. Malgré I'augmentation des contacts avec le reste du monde, le Charlevoisien est resté proche de son terroir et a su, avec plus ou moins de bonheur, conserver une différence qui fait encore l'admiration du visiteur.

Cependant, ce mềme Charlevoisien désire, comme tout le monde, vivre aujourd'hui et profiter pleinement des avantages de cette fin de siècle, sans se questionner, comme tout le monde, sur la standardisation de sa culture. Peu de gens s' intéressent à cette perte d'identité: I"histoire et la géographie régionales ne sont pas enseignées, le groupe d'interet Les Amis de Charlevoix, qui prône entre autres la protection des paysages et du patrimoine bati, fait figure de passéiste, les institutions culturelles sont plus ou moins fréquentées par la population et sont, de toutes façons, perçues comme des equipements touristiques.

L'industrie touristique contemporaine de Charlevoix vient de vivre un changement majeur d'orientation. Tout en conservant son image séculaire de région de destination - et non de circuit-, l'offre générale exploite désormais les attraits, les patrimoines, et non plus les services pour attirer les clientèles. La culture de Charlevoix, riche et diversifiée, cache encore des trésors à mettre à jour: ceci laisse présager la consolidation et la naissance de nouveaux équipements, dont le caractère sera principalement culturel et probablement à echelle locale, budgets obligent. Ceci laisse également présager que ces équipements, sollicités par une clientèle touristique et trop souvent batis par des promoteurs nouvellement adoptés par Charlevoix, seront d'abord et avant tout. parfois malgré leur volonté, upour touristes seulementw. Nul n'est prophète en son pays!

Dans le contexte culturel, l'origine du promoteur et la destination du produit n'ont aucune importance. Ce qui compte vraiment, c'est l'honnêteté avec laquelle le patrimoine charlevoisien est conservé et mis en valeur et les efforts consacrés à sa diffusion auprès de la clientèle régionale, tant par les promoteurs eux-mémes, association touristique en tête, que par les médias, maisons d'enseignement et groupes d'intérêt de Charlevoix.

Si par malheur les visités d'aujourd hui ne savent pas profiter du miroir, de cette image de leur culture que leur renvoient les visiteurs, peut-être leurs enfants serontils heureux, demain, de se retrouver une certaine identite dans ce musce à ciel ouvert, si imparfait et incomplet soit-il. Ultimement, comme dans tout tourisme qui se respecte, la rencontre entre visiteurs et visités aura encore eu le dessus.

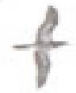

\section{NOTES}

1. Chouenner; Parler de tout et de rien. edire des merveilleso.

2. Le terme muse doit ici etre compris dans son sens le plus contemporain et dynamique possible.

\section{BIBLIOGRAPHIE}

Barbeau, Marius (1934), Au coewr du Ouebec. Les Editions du Zodiaque, Montrúal.

Bigshy, John M. (1840). The Shoe and the Canoe or Pictures of Travels in the Canodas. 2 tomes. Chapman \& Hall, Londres.

Chemin de fer national du Canada (c1925). Québec, la doulce province, deuxicme ćdition, Chemin de fer national du Canada, éditeur, Montréal.

Chouinard, Yvan (1997), La forge Cauchom de Riviere-Malbare. Joyau du parrimoine charleWoisiten, Direction des communications, ministere de la Culture et des communications, Quebec.

Des Gagniers, Jean (1994). Charlewoix, pays enchomle, Les Presses de I'Universite Lawil. Sainte-Foy.

Dube. Philippe (1986). Dewx rents ans de villegiature dams Charlevoix. Linspoire du parys visile". Les Presses de I'U niversité Laval, Sainte-Foy.

Gagnon, François-Mare el André Gendreau (1992). Clarence Gagnon. Calalogue d'exposition, Le Centre d'exposition. Baie-Saint-Paul.

Simard, Cyril (1988), Les papiers Saim-Gilles. herilaye de Felix-Anloine Savard. Les Presses de I'Universite Laval. Sainte-Foy.

Syndicat touristique de Charlevoix (1971), Both rowrishawe de Charlevoin. Pas d'editeur. 